\title{
Dynamic Workflow Enabled Advanced Predictive model in Outcome based Education
}

\author{
Shweta Dumbre, PhD \\ Ph.D Computer Science \\ Data Scientist \\ L \& T Infotech, USA
}

\author{
Sahil Karkhanis \\ Masters in Computer Science \\ Student at Rutgers University \\ New Brunswick, New Jersey, USA
}

\begin{abstract}
Research in the field of Academic Analytics has led to the development of various models which aim at analyzing the performance of students. The different objectives of these models include prediction of student's performance, providing feedback for supporting Instructors, student modelling, designing course curriculum and timetable scheduling. This research paper proposes an intervention model based on the existing NBA outcome based education system. The existing model includes the usage of parameters like the Program Educational Objectives (PEO's), Program Outcomes (PO's) and Course Outcomes (CO's). The paper also includes a case study which shows the application of the intervention model on educational data for 40 students of the B.Tech in Computer Science program. The intervention model uses the direct assessment performance of students as input and predicts the students who fail to attain the CO's. The intervention model results help in identifying the students who are in need of extra coaching and help the institution in focusing on these students in order to enhance the overall performance of the class. The automation of this model using artificial intelligent agents based model (iAERWS) further helps in improving the performance of the system significantly.
\end{abstract}

\section{Keywords}

Outcome based Education (OBE); performance prediction model; workflow management; academic analytics; dynamic change; education

\section{INTRODUCTION}

Outcome based educational (OBE) methods are being adopted at multiple levels throughout the world. These OBE theory focuses on the performance of the students in different kinds of assessments in order to achieve certain standard goals. The advantages of the OBE methods include clarity of focus, top down approach, flexibility. The students as well as the faculties are clear about the different assessments and assignments which contribute towards the course outcomes. The top down approach can be used to design the OBE model. The faculties start with the program outcomes at the start and then work their way downwards towards the different assessment and other academic quizzes which are to be conducted. Also the faculties get the flexibility to choose the different course outcomes which later will contribute towards the program outcomes.

An important extension to the conventional OBE model used by the National Board of Accreditation (NBA) is the predictive intervention module of CNQAA model. This module takes into consideration the performance of the students in the assessments already conducted. It then predicts whether the student is on the right track to attain the Course outcomes (CO's). The CNQAA results identify the students who have not been able to perform well. The faculty can then take extra efforts in coaching these students in order to enhance the overall class performance.

CampusNext ${ }^{\mathrm{TM}}$ is L\&T Infotech's comprehensive ready-touse cloud ERP which leverages innovative technologies such as virtualization, mobility and analytics to improve the the work life of all its stakeholders. It includes various modules including Admissions, Teaching-Learning Process, Examination Management, Student Portfolio, Faculty Support and collaboration, predictive Academic Analytics.

The Examination Management module takes care of the various internal assessments conducted at the academic institution. The grading of these assessments is also automated using the CampusNext ${ }^{\mathrm{TM}}$ functionality. The Student Portfolio module maintains a record of the academic performance of the students and their class participation. The Predictive Academic Analytics module automatically generates the academic performance reports and delivers them onto to role-based dashboards. The internal assessment data recorded by the CampusNext ${ }^{\mathrm{TM}}$ has been used for the case study describes in the paper.

The paper contains a case study which takes the marks obtained by 40 students in their second semester of B.Tech in Computer Science. The working of the intervention module with pre-fixed $\mathrm{CO}$ attainment targets is portrayed along with data analysis.

The further paper is arranged as follows - the second section talks about current state of art in the field of outcome based education methods and the use of intervention in academics to improve the student's performance. The third section briefly describes the overall modified architecture of the CampusNext $^{\mathrm{TM}}$ Quality Assurance Analytics (CNQAA) Model. The fourth section gives a detailed description of the predictive intervention module. The fifth section encloses a case study which shows the working of the CNQAA model and the improvement in the student's performance due to the predictive module. The paper concludes with future to the current model using the iAERWS automation model.

\section{LITERATURE REVIEW}

The Outcome Based Education (OBE) theory concentrates more on the outcomes than the inputs. It evaluates the students based on their academic performance in the different tests and quizzes conducted by the institute. The OBE framework is woven around the Program Educational Objectives (PEOs), Program Outcomes (POs) and Course Outcomes (Cos). These three parameters have to be mapped in order to form the backbone of the model.

The origination of outcome based education in the USA and its development in Australia has been talked about in [1]. The properties of OBE which include focus, top-down approach 
and flexibility have been elaborately explained in [1] and [2]. The different countries which accepted the Washington Accord which adopted the OBE concept are listed out in [3]

The merits and demerits of OBE have been explained in [4]. How can OBE be adopted in public schools, medical schools and higher educational educations has also been talked about. An introductory course, Managerial Accounting has been modified to shape up according to the OBE guidelines focusing more on the outcomes.

Outcome based education strategies which are employed in engineering programs in India are talked about it in [5].The OBE pyramid which contains institute vision, mission statement, program educational objectives and program outcomes are explained. The paper also talks about the selfassessment report which involves the program's compliance and performance with the OBE procedure. The 12 graduate attributes which are taken into consideration while auditing the institution's performance during the NBA audit process are enlisted.

The Accreditation Board for Engineering and Technology, Inc. (ABET) defines the PEOs as "broad statements that describe the career and professional accomplishments that the program is preparing graduates to achieve." The POs of a program are defined as "the knowledge, skills, or behaviors that a program's students should be able to demonstrate upon program completion." COs elaborate about what the learner will know and be able to do by the end of the course. A model described in [6] gives a basic structure as to how the PEOs, POs and the COs are supposed to be linked with each other. A model which is based on the OBE theory is elaborated in [6]. The paper elaborates on the how the assessments contribute towards the fulfillment of the program outcome. A mechanical engineering subject fluid mechanics has been taken as an example and shown as a case study, in which the linkages between the PO, CO and assessments have been explained. Procedure to calculate the $\mathrm{CO}$ attainment and the PO attainment have also been explained.

An experiment conducted by the Open Academic Analytics Initiative (OAAI) elaborated in [7], [8], and [9] elaborates about how the performance of the students was used to classify students into the At-Risk category or the normal category. The study of predictive modeling in academic domain in [10] was used to build the build the prediction model. Further the model shows the different methods which were employed to improve the student's performance after the intervention. Also the comparison of the student's performance after the intervention and without the intervention was studied.

\section{CNQAA MODEL ARCHITECTURE}

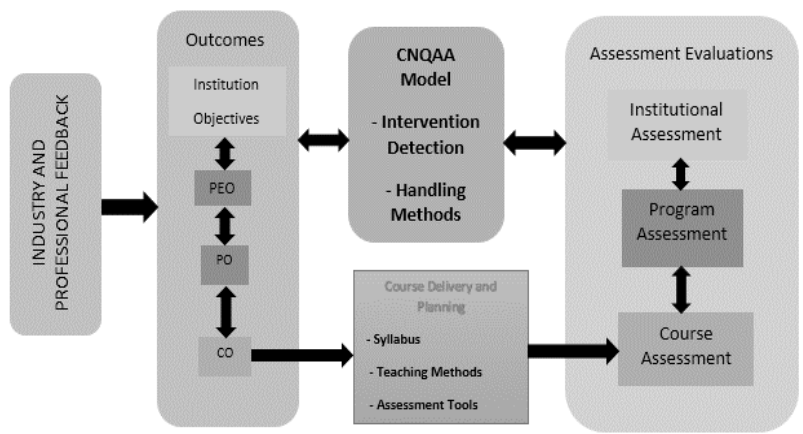

Figure 1 CNQAA Architecture - Basic
The CampusNext ${ }^{\mathrm{TM}}$ Quality Assurance Analytics (CNQAA) Basic Model uses a set of parameters like Program Educational objectives (PEO's), Program Outcomes (PO's) and Course Outcomes (CO's) as seen in Figure 1.

The Institutional objectives include the different program educational objectives (PEO's) with respect to each program offered by the institute. The PEO's have to be linked with the different Program Outcomes (PO's) as given in Table 1. The program outcome 1 relates to PEO1 and PEO2. Similarly, the $\mathrm{PO} 2$ relates to only $\mathrm{PEO} 3$ and so on.

Table 1 - Mapping of PO's with PEO's

\begin{tabular}{|c|c|c|c|c|c|}
\hline PEO & 1 & 2 & 3 & 4 & 5 \\
\hline PO1 & $\checkmark$ & $\checkmark$ & & & \\
\hline PO2 & & & $\checkmark$ & & \\
\hline PO3 & & $\checkmark$ & & & \\
\hline PO4 & & & & & $\checkmark$ \\
\hline
\end{tabular}

The next task is to form the course objectives of each and every course offered by the educational institute. Every course offered in every semester by any faculty has to be categorized in accomplishing certain goals which are the course outcomes. Again the program outcomes need to be linked closely with the course outcomes.

Table 2 - Mapping of PO's with CO's

\begin{tabular}{|c|c|c|c|c|c|}
\hline $\mathrm{PO}$ & $\mathrm{PO} 1$ & $\mathrm{PO2}$ & $\mathrm{PO3}$ & $\mathrm{PO} 4$ & $\mathrm{PO} 5$ \\
\hline $\mathrm{CO} 1$ & 3 & & 1 & & \\
\hline $\mathrm{CO} 2$ & 1 & 2 & & 1 & \\
\hline $\mathrm{CO} 3$ & & 1 & & & 3 \\
\hline $\mathrm{CO} 4$ & 1 & 1 & & 2 & \\
\hline
\end{tabular}

Table 2 describes an example of mapping between Program Outcomes and Course outcomes. The numbers 1 to 4 denote the significance of the course outcome in order to achieve the program outcome. $(1,2,3,4-$ In the increasing order of significance)

Course outcomes have to be evaluated on the basis of different direct assessments. The different tools which can be used for assessment of the PO can be classified into quantitative and qualitative. Quantitative includes the results in different assessments conducted by the university whereas qualitative includes extracurricular activities, Project and Industrial experience, placements, higher educational aspirants. Also the feedback from the students and the faculties after course completion, alumni feedback and industrial feedback can also contribute towards attainment of PO.

These assessments have to be preplanned and their structure has to be fixed. The different assessments would include written tests, quizzes or assignments and final exams. For the course outcomes to be evaluated they CO's have to be mapped with the assessments conducted at the educational institute. Figure 3 shows an example of distribution of $\mathrm{CO}$ on 
different factors where A-Assignment, UT- Unit Test, FE Final Exam, RES - Research Work.

Table 3 - Course outcome related assessments.

\begin{tabular}{|c|c|c|}
\hline $\begin{array}{c}\text { Course } \\
\text { Outcome }\end{array}$ & Assessment & Threshold \\
\hline CO1 & UT1,A1,A2, FE & X \\
\hline CO2 & UT1,A3,A4,FE & Y \\
\hline CO3 & UT2,A1,A3,FE,RES & Z \\
\hline CO4 & UT2,A2,A4,FE,RES & W \\
\hline CO5 & FE,RES & V \\
\hline
\end{tabular}

The values $\mathrm{X}, \mathrm{Y}, \mathrm{Z}, \mathrm{W}$, and $\mathrm{V}$ represent the threshold which a student should cross in order to attain the respective CO's.

Then a time frame has to be made which showcases when these assessments will be held during the course of the semester. Table 4 shows the tentative examination schedule throughout the semester.

Table 4 - CO's and assessments in chronological order

\begin{tabular}{|c|c|c|c|c|c|c|c|c|}
\hline $\begin{array}{l}\text { Course } \\
\text { Outco }\end{array}$ & \multicolumn{8}{|c|}{$\begin{array}{c}\text { Assessment Tools Timetable(Examinations in } \\
\text { chronological order) }\end{array}$} \\
\hline $\mathrm{CO} 1$ & A1 & UT1 & A2 & & M & & & $\mathrm{FE}$ \\
\hline $\mathrm{CO} 2$ & & UT1 & & A3 & I & & A4 & FE \\
\hline $\mathrm{CO} 3$ & A1 & & & A3 & D & UT2 & RES & $\mathrm{FE}$ \\
\hline $\mathrm{CO} 4$ & & & A2 & & S & UT2 & A4 & $\mathrm{FE}$ \\
\hline $\mathrm{CO} 5$ & A1 & & & & M & & RES & FE \\
\hline
\end{tabular}

Another table shows the weightage of the different assessments in the final attainment of the CO. An example of that is given in table 5 and table 6 .

Table 5 - Weightage Distribution of CO1

\begin{tabular}{|c|c|}
\hline Assessment & Weightage (\%) \\
\hline Assignment 1 & W1 \\
\hline Unit Test 1 & W2 \\
\hline Assignment 2 & W3 \\
\hline Final Exam & W4 \\
\hline Total & 100 \\
\hline
\end{tabular}

Table 6 - Weightage Distribution of $\mathrm{CO3}$

\begin{tabular}{|c|c|}
\hline Assessment & Weightage (\%) \\
\hline Assignment 1 & W1 \\
\hline Unit Test 2 & W2 \\
\hline Assignment 3 & W3 \\
\hline Research Work & W4 \\
\hline Final Exam & W5 \\
\hline Total & 100 \\
\hline
\end{tabular}

So at the end of the semester the attainment of the $\mathrm{CO}$ is calculated. For the $\mathrm{CO} 1$ the attainment percentage is calculated as follows after every score is normalized to $100-$

$\%$ CO Attainment score of a student $=\sum$ (Score in every dependent assessment $*$ Weightage)

$\%$ Attainment of $\mathrm{CO} 1=\mathrm{W} 1 *($ Score in $\mathrm{A} 1)+\mathrm{W} 2 *($ Score in $\mathrm{UT} 2)+\mathrm{W} 3 *($ Score in A2) $+\mathrm{W} 4 *($ Score in Final Exam $)$

$\%$ CO Attainment for the batch $=\%$ of students in the batch whose $\mathrm{CO}$ is Attained.

Later the \% Attainment of CO1 is compared to X threshold decided earlier. If the \% Attainment of $\mathrm{CO} 1>\mathrm{X}$ then $\mathrm{CO} 1$ is attained. Else CO1 is not attained.

Similarly the attainment of the CO's for all the students in a particular program can be calculated.

Once the $\mathrm{CO}$ attainment percentage is calculated the $\mathrm{PO}$ attainment $\%$ can be calculated in a similar manner by taking into consideration the weightage of the different CO's in attainment of the PO. The \% PO1 attainment is calculated as follows -

$\%$ PO Attainment score for a student $=\left[\sum\right.$ (Weightage of CO's $* \%$ of CO score) $] /\left[\sum\right.$ of Weightage $]$

$\%$ PO1 Attainment score for a student $=3 * 1$ (if $\mathrm{CO} 1$ is attained/ 0 if $\mathrm{CO} 1$ is not attained) $+1 * 1$ (if $\mathrm{CO} 2$ is attained/ 0 if $\mathrm{CO} 2$ is not attained) $1 * 1$ (if $\mathrm{CO} 4$ is attained/ 0 if $\mathrm{CO} 2$ is not attained)/ (5)

$\%$ PO Attainment for a batch $=\left[\sum\right.$ (Weightage of CO's * \% of $\mathrm{CO}$ attained students) $] /\left[\sum\right.$ of Weightage]

Similarly the \% PO attainment scores can be calculated for all the other PO's. The total number of POs attained by the batch determines the effectiveness of the program. The threshold for the program to be accredited can be decided by the institution.

The feedback from the students and the faculties regarding the courses and the methods of teaching can be taken into consideration while mapping the PO's and CO's. The industrial feedback and alumni feedback can also give insights into the different changing industrial trends which should be incorporated in the curriculum.

\section{CNQAA MODEL - PREDICTIVE INTERVENTION MODULE}

A noteworthy additional feature added to NBA model is the predictive intervention module. The purpose of adding this 
module is to improve the performance of the students whose marks are not up to the mark till the mid semester. Every student enrolled in a particular program is kept under a constant check by the predictive intervention module.

Table 7 - Chronological order of the assessments conducted in a semester.

\begin{tabular}{|c|c|c|}
\hline $\begin{array}{l}\text { Assessment Name } \\
\text { before Midsem }\end{array}$ & Time & $\begin{array}{l}\text { Assessment Name } \\
\text { after Midsem }\end{array}$ \\
\hline $\begin{array}{c}\text { Assignment } 1 \text { (10 } \\
\text { Marks) }\end{array}$ & \multirow{4}{*}{$\begin{array}{l}\text { MID } \\
\text { SEM }\end{array}$} & $\begin{array}{c}\text { Assignment } 3 \text { (10 } \\
\text { Marks) }\end{array}$ \\
\hline Unit Test 1 (50 Marks) & & Unit Test 2 (50 Marks) \\
\hline $\begin{array}{c}\text { Assignment } 2 \text { (10 } \\
\text { Marks) }\end{array}$ & & $\begin{array}{c}\text { Assignment } \\
\text { 4/Research (10 Marks) }\end{array}$ \\
\hline & & $\begin{array}{c}\text { Final Exam (100 } \\
\text { Marks) }\end{array}$ \\
\hline
\end{tabular}

If we set a target of $\mathrm{X}$ (where $\mathrm{X}=\mathrm{CO}$ attainment target) to attain a particular $\mathrm{CO}$. The predictive intervention module for the particular curriculum pattern can be designed as follows -

Table 8 - Splitting of assessments into sections

\begin{tabular}{|c|c|}
\hline Section 1 & Section 2 \\
\hline Assignment 1 & Assignment 3 \\
\hline Unit Test 1 & Unit Test 2 \\
\hline Assignment 2 & Assignment 4 \\
\hline & Final Exam \\
\hline
\end{tabular}

The target $\mathrm{X} \%$ can be split into the following format which can be customized as per requirements.

Table 9 - Weightage Distribution to achieve target

\begin{tabular}{|c|c|}
\hline Section $1(\%)$ & Section $2(\%)$ \\
\hline $\mathrm{T}$ & $\mathrm{U}$ \\
\hline
\end{tabular}

So a student has to get minimum $\mathrm{T} \%$ of $\mathrm{X}$ in section $1+\mathrm{U} \%$ of $\mathrm{X}$ in section to attain the CO. After the section 1 assessments are over the intervention module works in the following manner as shown in the figure 2 .

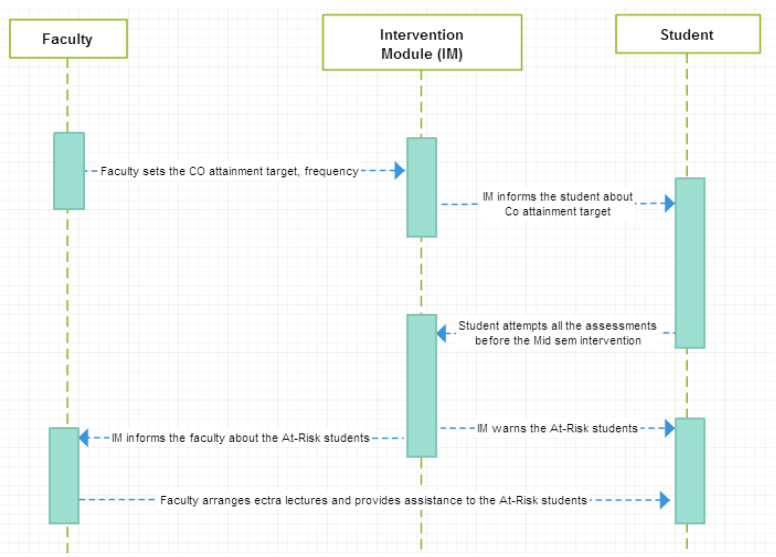

Figure 2 Sequence Diagram Intervention Module

Once the student's at academic risk are predicted by the intervention module, there are two options which can be employed by the institute. The intervention module can be programmed to send an automated text to the At-Risk students to warn him to improve his performance. Another alternative is to inform the faculty about the At-Risk students. Then the faculty can take the necessary measures to warn the students and to provide assistance to the At-Risk students.

\section{CASE STUDY}

The case study describes the working of the CNQAA model and its intervention module.It helps in identifying the At-Risk students from the class. The semester 2 scores of the students are considered for this case study.

Considerations -

Number of Students

Program

Semester

Time Period

Second

Course

Sept 2013 to Dec 2013

$\mathrm{C}++$

PO1- An ability to apply analysis, design, development, and testing principles in the construction of software systems in $\mathrm{C}++$; an ability to function effectively on a software development team

CO1 - The student should be familiar with the basics of C Language

CO3 - The student should be acquainted to the object oriented concepts of $\mathrm{C}++$

CO5 - The student should be able to write functions and procedures in $\mathrm{C}++$.

The mapping of the PO1 with the respective CO's are given in the table 10 .

Table 10. PO1 and its contributing CO's with weightage

\begin{tabular}{|c|c|c|}
\hline \multirow{2}{*}{ PO } & $\begin{array}{c}\text { Dependent } \\
\text { CO's }\end{array}$ & Weightage \\
\hline \multirow{3}{*}{ PO1 } & $\mathrm{CO} 1$ & 4 \\
\cline { 2 - 3 } & $\mathrm{CO} 3$ & 3 \\
\cline { 2 - 3 } & $\mathrm{CO} 5$ & 2 \\
\hline
\end{tabular}

The different assessments which are going to be held for the courses $\mathrm{CO} 1, \mathrm{CO} 3$ and $\mathrm{CO} 5$ are given in table 11 along with their total marks and weightage.

The PO1 attainment target is set to $75 \%$ and the corresponding course outcome thresholds are set to $60 \%$ for $\mathrm{CO} 1, \mathrm{CO} 3$ and $\mathrm{CO} 5$. The academic data of the students included in the CampusNextTM reports has been shown in a tabular format.

As the threshold for attainment of $\mathrm{CO} 1, \mathrm{CO} 3$ and $\mathrm{CO} 5$ was set to $60 \%$. Section 1 targets were calculated in order to attain the respective CO's at the end of the semester. Based on these section 1 targets the students were categorized into Academically At-Risk students and normal category students. The intervention module further focuses on the At-Risk students. Model used for prediction was Linear Regression.

The average performance of the At-risk students for all the assessments without intervention for all the $3 \mathrm{CO}$ 's is shown in table 13 
Table 11. Assessments scheduled for semester 2 in chronological order with weightage

\begin{tabular}{|c|c|c|c|}
\hline Section & $\begin{array}{c}\text { Assessment } \\
\text { Name }\end{array}$ & Total Marks & $\begin{array}{l}\text { Weightage } \\
\text { (in \%) }\end{array}$ \\
\hline \multirow{4}{*}{ Section 1} & $\begin{array}{c}\text { Assignment } \\
1(\mathrm{~A} 1)\end{array}$ & 10 & 5 \\
\hline & $\begin{array}{c}\text { Assignment } \\
2(A 2)\end{array}$ & 10 & 5 \\
\hline & $\begin{array}{l}\text { Unit Test } 1 \\
\text { (UT1) }\end{array}$ & 50 & 20 \\
\hline & \multicolumn{3}{|c|}{ MID SEM BREAK } \\
\hline \multirow{5}{*}{ Section 2} & $\begin{array}{c}\text { Assignment } \\
3 \text { (A4) }\end{array}$ & 10 & 5 \\
\hline & $\begin{array}{c}\text { Assignment } \\
4 \text { (A4) }\end{array}$ & 10 & 5 \\
\hline & $\begin{array}{c}\text { Unit Test } 2 \\
\text { (UT2) }\end{array}$ & 50 & 20 \\
\hline & $\begin{array}{l}\text { Final Exam } \\
\qquad(\mathrm{FE})\end{array}$ & 100 & 40 \\
\hline & Total & 240 & 100 \\
\hline
\end{tabular}

Table 12. Average scores determining section 1 scores

\begin{tabular}{|c|c|c|c|c|c|c|c|}
\hline \multirow[b]{2}{*}{$\begin{array}{l}\mathrm{CO} \\
(\mathrm{N}=4 \\
0)\end{array}$} & \multicolumn{6}{|c|}{ SECTION 1 ASSESSMENT SCORES } & \\
\hline & $\begin{array}{l}\text { A1 } \\
\text { scor } \\
\text { e }\end{array}$ & $\begin{array}{l}\text { UT1 } \\
\text { scor } \\
\text { e }\end{array}$ & $\begin{array}{l}\text { A2 } \\
\text { scor } \\
\text { e }\end{array}$ & $\begin{array}{l}\text { A1 } \\
\text { contri }\end{array}$ & $\begin{array}{l}\text { UT1 } \\
\text { contri }\end{array}$ & $\begin{array}{l}\text { A2 } \\
\text { contri }\end{array}$ & $\begin{array}{l}\text { Section } 1 \\
\text { total }\end{array}$ \\
\hline $\mathrm{CO} 1$ & 5.33 & $\begin{array}{l}32.4 \\
5\end{array}$ & 5.58 & 2.66 & 12.98 & 2.79 & 18.43 \\
\hline $\mathrm{CO} 3$ & 5.35 & 34.9 & 6.38 & 2.68 & 13.96 & 3.19 & 19.82 \\
\hline $\operatorname{co5}$ & 6.4 & $\begin{array}{l}33.8 \\
8\end{array}$ & 6.23 & 3.2 & 13.55 & 3.11 & 19.86 \\
\hline
\end{tabular}

Table 13. Prediction of Performance without intervention

\begin{tabular}{|l|l|l|l|l|l|l|l|l|}
\hline \multirow{2}{*}{ c0 } & \multicolumn{7}{|c|}{ ASSESSMENT SCORES } & \\
\cline { 2 - 9 } & $\begin{array}{l}\text { A1 } \\
\text { scor } \\
\text { e }\end{array}$ & $\begin{array}{l}\text { UT1 } \\
\text { scor } \\
\text { e }\end{array}$ & $\begin{array}{l}\text { A2 } \\
\text { scor } \\
\text { e }\end{array}$ & $\begin{array}{l}\text { A3 } \\
\text { scor } \\
\text { e }\end{array}$ & $\begin{array}{l}\text { UT2 } \\
\text { scor } \\
\text { e }\end{array}$ & $\begin{array}{l}\text { A4 } \\
\text { scor } \\
\text { e }\end{array}$ & $\begin{array}{l}\text { FE } \\
\text { scor } \\
\text { e }\end{array}$ & $\begin{array}{l}\text { Total } \\
\text { score }\end{array}$ \\
\hline CO1 & 4.25 & 26.5 & 5.56 & 5.25 & $\begin{array}{l}27.6 \\
2\end{array}$ & 5.25 & $\begin{array}{l}56.4 \\
3\end{array}$ & 54.38 \\
\hline
\end{tabular}

\begin{tabular}{|l|l|l|l|l|l|l|l|l|}
\hline CO3 & 5 & $\begin{array}{l}23.3 \\
6\end{array}$ & 6 & 5.27 & $\begin{array}{l}27.6 \\
3\end{array}$ & 5.09 & $\begin{array}{l}51.3 \\
6\end{array}$ & 51.62 \\
\hline CO5 & 5.4 & 23.7 & 5.6 & 5.7 & 27.8 & 4.8 & 50.6 & 51.59 \\
\hline
\end{tabular}

The detailed results of the intervention algorithm were as follows -

Table 14 describes the performance of the students in the section 1 and determines the number of students who are on the right track to attain the respective CO's at the end of the semester.

\section{PERFORMANCE WITHOUT INTERVENTION}

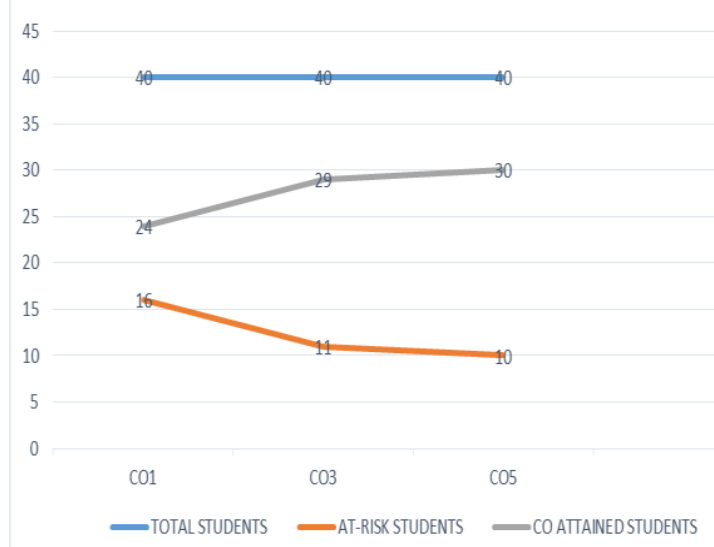

Figure 3 Prediction of Number of At-Risk students for every CO

Table 14. Prediction of At-Risk student's performance for all 3 CO's without intervention

\begin{tabular}{|c|c|c|c|}
\hline CO & $\begin{array}{c}\text { Total } \\
\text { students }\end{array}$ & $\begin{array}{c}\text { At-Risk } \\
\text { students }\end{array}$ & $\begin{array}{c}\text { CO } \\
\text { attained } \\
\text { students }\end{array}$ \\
\hline CO1 & 40 & 16 & 24 \\
\hline CO3 & 40 & 11 & 29 \\
\hline CO5 & 40 & 10 & 30 \\
\hline
\end{tabular}

Figure 4 gives a detailed overview regarding the $\mathrm{CO}$ and $\mathrm{PO}$ attainment without intervention.

Table 15 Prediction of $\mathrm{CO}$ and $\mathrm{PO}$ attainment without intervention

\begin{tabular}{|c|c|c|c|}
\hline CO & $\begin{array}{c}\text { CO } \\
\text { attainment } \\
\text { (in \%) }\end{array}$ & Weightage & $\begin{array}{c}\text { PO } \\
\text { attainment } \\
\text { (in \%) }\end{array}$ \\
\hline CO1 & 60 & 4 & \multirow{2}{*}{67.5} \\
\cline { 1 - 2 } CO3 & 72.5 & 3 & \\
\hline CO5 & 75 & 2 & \\
\hline
\end{tabular}




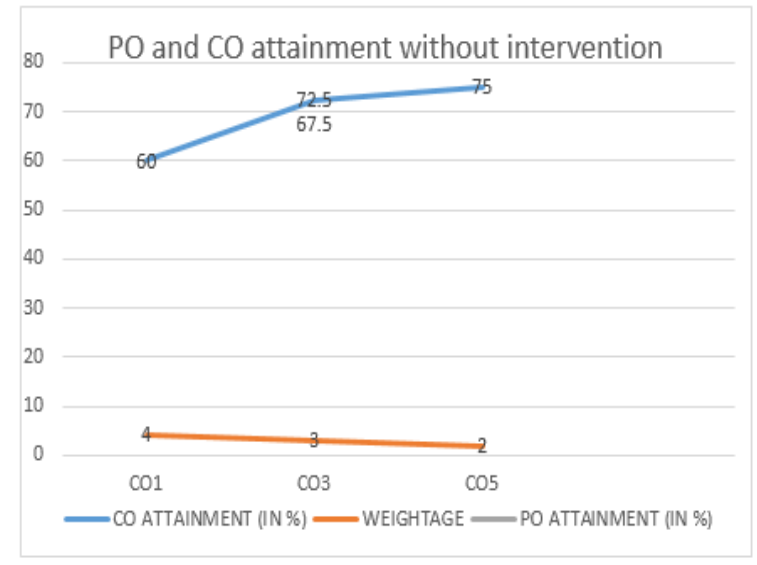

Figure 4 Prediction of PO and CO attainment without intervention

Once these At-Risk students have been predicted, the institution should provide them with extra resources in order to increase their understanding of the subject. The faculty should devote time in understanding the weak topics of these students, whether he needs to change the teaching method of certain topics to aid understanding. These extra efforts put in by the faculty and the students will definitely help the students in the long run and increase the $\mathrm{CO}$ attainment and thus the PO attainment.

The steps involved were automated using iAERWS [11] (intelligent agent rule based workflow system). The observations collected after selection of dependent variables like weightage, $\mathrm{PO}, \mathrm{CO}$ and PEO's and its prediction of the at-risk students helped select the best time to run the intervention model. The automation lead to giving flexibility to observe the impacts of choosing different parameters ahead of time. The CNQAA Basic model with iAERWS model leads to the enhanced CNQAA model to manage change at runtime.

\section{CONCLUSION}

The addition of the predictive intervention module in the already existing NBA outcome based model is an advantage. The students and the faculty get an indication about their progress in the current semester. The faculties also get to know the different students who need to be given extra attention. The case study helps in predicting the At-Risk students from a batch of 40 students. This helps in the attainment of the institutional objectives and enhances the reputation of the program offered by the institute.

\section{FUTURE WORK}

The current CNQAA model focusses mainly on the direct assessments conducted by the institute which mainly included assignments, Unit Tests, research work and Final exam. The model can also take into consideration the indirect assessments like feedback from the students, faculties, industry and alumni. These can also be given weightage in contributing towards the attainment of CO's and indirectly the CO's. Whereas the enhanced version CNQAA with iAERWS offers flexibility to the users to observe the impact of change in the model at runtime on the fly.

The data recorded by the CampusNext ${ }^{\mathrm{TM}}$ can be kept as a record and can be formatted into detailed reports. These reports can be used to monitor the progress of the academic institution and the quality of the education provided over the years. The inability to achieve the set targets can alert the institution to think about other solution. These reports can also count as sufficient proof to voice out the improvement in the PO attainment of the program which can be submitted to the NBA during their audits.

\section{REFERENCES}

[1] Anna Alderson and Marie Martin, Outcome based education: Where has it come from and where is it going. Issues in Educational Research, 17(2) 2007, pp. 161-182.

[2] Dr ACR Tavner Outcomes-based education in a University setting Australasian Journal of Engineering Education, Copyright AAEE, 2005, ISSN 1324-5821 pp. $1-14$

[3] T. A. Janardhan Reddy, P. Srinivas Reddy. Outcome Based Education-Some Initiatives Open Journal of Social Sciences, October 2014, 2, 7-11 pp. 7-11.

[4] Gladie Lui and Connie Shum. Outcome-based education and student learning in managerial accounting in Hong Kong Journal of Case Studies in Accreditation and Assessment pp. 1-13

[5] Sreekanth $N V$, Arjun CC and Dr. K Guruprasad. Outcome Based Education: Strategies and tools for Indian scenario Journal of Engineering Education Transformations, Special Issue: Jan. 2015, eISSN 23941707 pp. 348-352.

[6] Zamri Mohamed, Mohd Yusof Taib, M.S. Reza Assessment Method for Course Outcome and Program Outcome in Outcome Based Education (OBE) Proceedings of MUCET2010 Malaysian Technical Universities Conference on Engineering and Technology June 28-29, 2010 pp. 1-4.

[7] Eitel J.M. Lauría, Joshua D. Baron, Mallika Devireddy, Venniraiselvi Sundararaju, Sandeep M. Jayaprakash, Mining academic data to improve college student retention: An open source perspective LAK'12, 29 April - 2 May 2012, Vancouver, BC, Canada Copyright 2012 ACM 978-1-4503-1111-3/12/04

[8] Eitel J.M. Lauría, Erik W. Moody, Sandeep M. Jayaprakash, Nagamani Jonnalagadda, Joshua D. Baron, Open Academic Analytics Initiative: Initial Research Findings LAK '13, April 08 - 12 2013, Leuven, Belgium Copyright 2013 ACM 978-1-4503-17856/13/04

[9] Sandeep M. Jayaprakash, Erik W. Moody, Eitel J.M.Lauría, James R. Regan, and Joshua D. Baron, Early Alert of Academically At-Risk Students: An Open Source Analytics Initiative Journal of Learning Analytics, 1(1), pp 6-47

[10] Sahil P. Karkhanis, Shweta S. Dumbre A Study of Application of Data Mining and Analytics in Education Domain 10.5120/21393-4436

[11] Shweta Tayade, Vinay Chavan, Flexibility Analysis in Business Process Reengineering with Theory of Constraint using Intelligent Dynamic Workflow System. 10.5120/13915-1821, International Journal of Computer Applications, Volume 80 - Number 12 